\title{
Oxidative degradation of non-recycled and recycled paper
}

\author{
Floriana Coppola • Alberto Modelli
}

Received: 13 May 2020/Accepted: 10 August 2020/Published online: 28 August 2020

(C) The Author(s) 2020

\begin{abstract}
The degradation of paper-based materials involves several and complex mechanisms, such as hydrolysis and oxidation. The behaviour of different types of pulps can be very variable. In this study, the difference upon oxidation of contemporary non-recycled and recycled papers, which now constitute a considerable fibre source, is investigated. A $0.015 \mathrm{M}$ potassium periodate solution is used to oxidise five types of paper, two non-recycled and three recycled, for $0.5,1,2$ and $4 \mathrm{~h}$. The effects of such oxidation treatments are evaluated in terms of carbonyl content and degree of polymerisation (DP). A modified procedure of the Szabolcs's method and viscometry are used to measure the carbonyl content and DP, respectively. The carbonyl groups are found to
\end{abstract}

increase more rapidly in the recycled papers than in the non-recycled ones. On the contrary, oxidation causes a larger decrease of the DP values in the nonrecycled papers, the paper made of pure cellulose being the most sensitive in terms of depolymerisation. The DP values measured for pure cellulose paper are in line with previously reported data. Moreover, in accordance with the Ekenstam equation, the plots of the reciprocal of DP as a function of oxidation time show good linear correlations for all types of paper investigated. Pseudo rate constants are thus calculated from the slopes of these plots, those of the nonrecycled papers being found to be higher than those of the recycled papers.
F. Coppola $(\bowtie) \cdot$ A. Modelli

Dipartimento di Chimica "G. Ciamician", Università di

Bologna, via Selmi 2, 40126 Bologna, Italy

e-mail: floriana.coppola2@unibo.it

\section{A. Modelli}

Centro Interdipartimentale di Ricerca in Scienze

Ambientali, via S. Alberto 163, 48123 Ravenna, Italy 


\section{Graphic abstract}

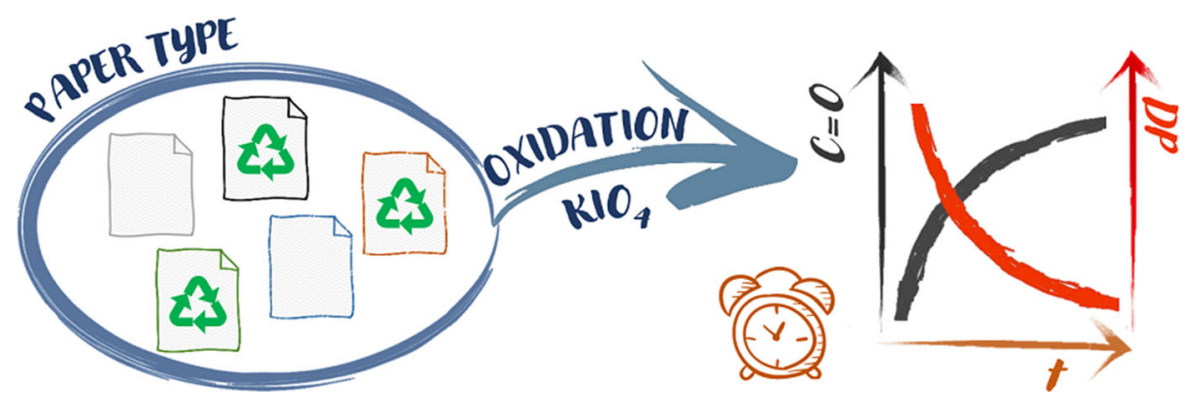

Keywords Periodate oxidation of paper - Recycled paper - Carbonyl content - Degree of polymerisation

\section{Introduction}

Technologies and raw materials for papermaking have radically changed over the centuries (Hunter 1978). While around 1850 wood fibres (softwood and hardwood) started being used to manage the ever-increasing demand for paper and deficiency of rag fibres, currently a growing part of paper manufacturing involves recycled fibres due to economic and environmental issues (CEPI 2017). The 2018 monitoring report published in the context of the European Declaration on Paper Recycling 2016-2020 outlines that the recycling rate in Europe reached $71.6 \%$ in 2018, increasing by 47\% since 1998 (EPRC 2019). Unlike the well-studied Western historical paper for which significant research has been carried out over the past decades, scientific research on contemporary recycled paper is quite limited. It has previously been reported (Coppola et al. 2018a) that accelerated degradation experiments, carried out exposing recycled and non-recycled papers to extreme conditions of temperatures $\left(50-80{ }^{\circ} \mathrm{C}\right)$ and relative humidity levels (26-98\%), led to a systematic difference between the degradation rates of the recycled and non-recycled paper, albeit negligible considering the experimental limits. This finding could be traced back to a different extent of oxidative degradation. Therefore, in the present study, the extents of oxidative degradation in different papers are evaluated measuring its effects on DP in order to give insight into the behaviour of contemporary recycled and non-recycled paper upon oxidation.

In general terms, the paper produced centuries ago and that manufactured nowadays can be considered as the same product, that is a sheet material made of a network of various fibres (e.g., rag, straw, wood, recycled) which have been deposited from an aqueous suspension (Roberts 1996). However, different types of paper can degrade with different rates (Barański et al. 2000, 2003), so that studies of degradation can allow predictions on their durability. Knowledge of mechanisms of cellulose degradation is a fundamental issue in preventive and interventive conservation of both historical and contemporary documents.

Regardless of its source, the main structural component of paper is cellulose, a linear condensation polymer consisting of $\mathrm{D}$-anhydroglucopyranose units linked by $\beta$-1,4-glycosidic bonds. The morphological structure of cellulose can be very complex because of the ability of hydroxyl groups to form both inter- and intra-molecular hydrogen bonds (Nevell and Zeronian 1985). The complexity of the cellulose-based materials is reflected by the numerous degradation reactions which can occur (Zervos 2010; Area and Cheradame 2011), acid-catalysed hydrolysis and oxidation being among the main chemical reactions (Sistach et al. 1998; Porck 2000; Margutti et al. 2001). Hydrolysis takes place with the protonation of a glycosidic oxygen atom by a hydrogen ion, followed by the breakage of a glycosidic bond and splitting of the cellulose chain with consequent decrease in the degree of polymerisation (DP) (Nevell 1985a). Oxidation can proceed through several reaction paths, such as oxidation of the primary and secondary hydroxyl groups of the pyranose ring to carbonyl and carboxyl 
groups (Margutti et al. 2001), as well as free radical reactions (Kolar 1997; Jeong et al. 2014). Oxidising agents have been classified as non-specific or specific (Margutti et al. 2001), according to the positions of the pyranose ring they attack (random or defined, respectively). Sodium hypochlorite is considered a nonspecific oxidant and may give rise to different products. In contrast, the periodate oxidation of cellulose leads to breaking of the bond between the $\mathrm{C} 2$ and C3 ring atoms, with formation of 2,3dialdehyde cellulose (Varma and Chavan 1995). Oxidation reactions themselves can cause ring opening and increase of acidity due to the formation of carboxyl groups, weakening the glycosidic bonds and inducing hydrolytic depolymerisation (Margutti et al. 2001). Moreover, the formation of electron-acceptor groups such as carbonyl groups in the neighbourhood of the glycosidic oxygen has been held accountable for favouring hydrolysis (Krässig 1993). Therefore, cellulose degradation should be regarded as a mixed hydrolytic and oxidative mechanism, where the two reactions are autocatalytically accelerated (Sistach et al. 1998; Łojewska et al. 2005). In a very recent study (Tétreault et al. 2019), which describes a model for simulating the degradation of paper-based materials, oxidation was not included in the model due to the lack of data.

The prevalent mechanisms of degradation and their rates are functions of both paper properties (e.g., $\mathrm{pH}$, lignin content, metal ions) and storage conditions (e.g., temperature, humidity, gaseous pollutants). It is well known that most of the paper produced between 1850 and 1950 using rosin sizing is acidic, and thus prone to a faster degradation than that produced before with other sizing materials (e.g., flour, gelatine) (Strlič et al. 2005a). pH plays a crucial role in the acidcatalysed hydrolysis, the lower the $\mathrm{pH}$, the faster the degradation. A number of methods have been proposed to measure $\mathrm{pH}$ either by extraction (Strlič et al. 2004; ASTM D778-97 2007; TAPPI T509 om-15 2015) or surface determination (TAPPI T529 om-14 2014).

The chemical and physical paper properties may be altered to different extents depending on the main degradation mechanisms. For instance, yellowing is ascribed to the formation of carbonyl groups (Mosca Conte et al. 2012). Degradation experiments, during which paper samples are exposed to extreme conditions of temperature, humidity and/or pollutants, have been carried out to determine the effects and rate of degradation by measuring the property of interest as a function of time with suitable techniques (Zou et al. 1996; Porck 2000; Margutti et al. 2001; Strang and Grattan 2009; Whitmore and Bogaard 2009; Kačík et al. 2009; Strlič et al. 2011; Coppola et al. 2018a). The determination of DP, a measure of the average molecular weight, is among the most investigated chemical properties of cellulosic materials. Although more precise techniques are now available, such as size exclusion chromatography (Strlič and Kolar 2003; Dupont and Mortha 2004; Łojewski et al. 2011), viscometry is still the most commonly used technique due to its relatively simple and fast procedure (Strlič et al. 2005b). DP measurements are especially important in connection with kinetic studies of paper degradation. Measurements of the extent of oxidised groups in cellulose is also important. The determination of oxidised carbonyl groups and DP is meaningful also for non-degraded cellulosic materials, where the presence of oxidised groups can be due to the pulping and bleaching processes (Biermann 1996), and for evaluation of appropriate conservation procedures (Bicchieri et al. 1999, 2016; Malesic et al. 2002). The determination of carbonyl groups presents inherent difficulties, such as low average contents (in the $\mu \mathrm{mol} \mathrm{g}^{-1}$ range) and possible incompleteness of derivatisation reactions due to problems of accessibility to functional groups (Röhrling et al. 2002). To estimate the amount of carbonyl groups in cellulose several analytical procedures have been reported (Szabolcs 1961; Nevell 1985b; Strlič and Pihlar 1997; Bicchieri et al. 1999; Röhrling et al. 2002; TAPPI T430 cm09 2009), such as the determination of copper number (TAPPI T430 cm-09 2009), the cyanide method (Nevell 1985b) and fluorescence labelling (Röhrling et al. 2002). Fourier transform infrared (FTIR) spectroscopy has been also applied to investigate the formation of carbonyl groups (Margutti et al. 2001), however, the presence of non-bonded water can mask possible changes in the carbonyl region, not allowing easy recognition of oxidised functional groups (Ali et al. 2001; Coppola et al. 2018b).

In the present study, the effects of oxidation on paper samples immersed in a solution with a 
specific oxidising agent (periodate), for different durations, were evaluated in terms of DP and carbonyl contents. Five different paper types, virgin non-recycled and recycled papers, were analysed in order to evaluate possible differences in the degradation effects. In particular, the present results focus on the correlation between oxidation time and carbonyl content, and between carbonyl content and DP.

\section{Experimental}

\section{Materials}

Five types of paper, two made of non-recycled fibres and three made with different proportions of recycled fibres, were analysed. The two samples made of nonrecycled fibres are Whatman filter paper No 1 (Maidstone, UK) and Arcoprint $1 \mathrm{EW}$ paper (Fedrigoni, Italy). The three samples with $30 \%, 80 \%$ and $100 \%$ of recycled fibres are, respectively, Nautilus (Mondi, UK), Woodstock (Fedrigoni, Italy) and OfficeDEPOT (OfficeDEPOT, US). Below these five types of paper are designated with the labels: Wh for Whatman, A for Arcoprint $1 \mathrm{EW}, \mathrm{RN}$ for Nautilus, RW for Woodstock, and RU for OfficeDepot. The recycled fibres of RW are pre-consumer, namely, for instance, derived from manufacturing scrap, while those of RU are post-consumer, thus reclaimed after having been used from a consumer (CEPI 2009). In our previous works (Coppola et al. 2017, 2018a), the fibre furnish analysis and phloroglucinol test were carried out and turned out that all samples, except Wh, are made of chemical pulps with both softwood and hardwood fibres. Additionally, all paper samples, except Wh, have a substantial amount of ash (more than 10\%) and traces of lignin (Coppola et al. 2017, 2018a).

\section{Oxidation}

The samples were oxidised by immersion in potassium metaperiodate $\left(\mathrm{KIO}_{4}\right) 0.015 \mathrm{M}$ aqueous solutions for $0.5,1,2$ and $4 \mathrm{~h}$ at $20 \pm 5{ }^{\circ} \mathrm{C}$. For each sample, about $400 \mathrm{mg}$ of paper were immersed in $50 \mathrm{~mL}$ of oxidising solution. Immediately after oxidation, the oxidised samples were immersed in distilled water for $15 \mathrm{~min}$, washed thoroughly and air-dried.
Analytical methods

The non-degraded and degraded (oxidised) paper samples were analysed in terms of acidity, DP and carbonyl content.

The cold extraction method with the modifications suggested by Strlič et al. (2004) was carried out to measure the $\mathrm{pH}$ of all paper samples. The samples were weighed $(6.6 \pm 0.6 \mathrm{mg})$ and put into $1.5 \mathrm{~mL}$ vials, where a determined volume $(462 \pm 42 \mu \mathrm{L})$ of MilliQ water was added. The $\mathrm{pH}$ of the cold extraction was measured using a semi micro-combined glass electrode (32200383, XS Instruments, Italy). For each sample, $\mathrm{pH}$ was measured in triplicate. The $\mathrm{pH}$ value, rounded to the nearest 0.1 decimal digit, was acquired when a constant reading was reached. The mean uncertainty for alkaline paper using this procedure was evaluated to be \pm 0.3 (Strlič et al. 2004).

A Bruker ATR-FTIR spectrometer with OPUS software (Vers. 7.5) was used to measure the absorbance spectra of non-degraded samples over the range $4000-400 \mathrm{~cm}^{-1}$. 64 scans were acquired with a resolution of $4 \mathrm{~cm}^{-1}$ to calculate the crystallinity index using the ratio between the absorption at 1372 and $2900 \mathrm{~cm}^{-1}$ (Kato and Cameron 1999; Łojewski et al. 2010).

The DP values were determined by viscometry using the cupriethylendiamine (CED) solvent as indicated by the standard ISO 5351 (2010). However, prior to dissolution, a reduction pre-treatment was carried out to stabilise oxidised cellulose, because of detrimental effects of CED due to its alkaline $\mathrm{pH}$ (about 11) (Strlič et al. 1998). Therefore, degraded and non-degraded samples were reduced with a $\mathrm{NaBH}_{4}$ $0.01 \mathrm{M}$ aqueous solution for $24 \mathrm{~h}$ under room conditions. After reduction, the samples were rinsed with diluted acetic acid (pH 5) and washed thoroughly with distilled water. The air-dried stabilised samples were weighed, then immersed and stirred in a precise volume of distilled water. When a pulp was obtained, an equal volume of fresh CED $1 \mathrm{M}$ was added, and the solution mixed again until the sample was completely dissolved. The efflux time of each solution passing through an Ubbelohde viscosimeter $(53210 \mathrm{I}$, Schott Gerate, Germany) at $25.0 \pm 0.1^{\circ} \mathrm{C}$ was measured automatically using a ViscoSystem (AVS 310, Schott Gerate, Germany). The product between the measured efflux time and viscosimeter constant $\left(0.0086 \mathrm{~s}^{-1}\right)$, obtained from the calibration procedure (ISO 5351 
$2010)$, gives the viscosity ratio $\left(\eta_{\text {ratio }}\right)$. For values of $\eta_{\text {ratio }}$ from 1.0 to 19.9, the standard ISO5351 (2010) provides the corresponding values of the product between the intrinsic viscosity $[\eta]\left(\mathrm{mL} \mathrm{g}^{-1}\right)$ and the known mass concentration $\rho$ of the sample $\left(\mathrm{g} \mathrm{mL}^{-1}\right)$, calculated subtracting dry and ash contents from the weight of the sample. It was thus possible to calculate the DP values using the Mark-Houwink-Sakurada equation (Flory 1953) with the coefficients proposed by Evans and Wallis (1987):

$\mathrm{DP}^{0.85}=1.1[\eta]$

The DP calculated for each paper sample was the average of two independent measurements. The mean uncertainty of DP determinations was evaluated to be less than $2 \%$, except for the RN paper (9\%).

The carbonyl content was measured following the method originally proposed by Szabolcs (1961) and optimised by Strlič and Pihlar (1997). About $10 \mathrm{mg}$ of paper samples were put in an open $10 \mathrm{~mL}$ glass tube. $0.5 \mathrm{~mL}$ of $\mathrm{KOH} 0.3 \mathrm{M}$ and $0.5 \mathrm{~mL}$ of 2,3,5-triphenyltetrazolium chloride (TTC) $0.01 \mathrm{M}$ were added, and heated in a water bath at $80{ }^{\circ} \mathrm{C}$ for 6 min. After immediate cooling to room temperature, the solution with the sample was filtered and rinsed with methanol in a laboratory flask until the $10 \mathrm{~mL}$ mark was reached. In alkaline medium, the oxidation of carbonyl groups (aldehydes and ketones, the latter previously converted into aldehyde through alkaline hydrolysis) into carboxyl groups, and the consequent reduction of TTC into triphenylformazane (formazane), with its typical red colour, allows the determination of carbonyl content by measuring the absorbance of formazane at $482 \mathrm{~nm}$. The absorbance (Abs) of the resulting solution, kept in the dark due to light sensitivity, was measured within $60 \mathrm{~min}$ from the preparation. A UV-Vis Cary 60 spectrophotometer (Agilent Technologies Inc, US) with the CaryWinUV Scan software (Vers. 5.0.0.999) was used to measure the absorbance in the 400-600 nm wavelength range with a resolution of $1 \mathrm{~nm}$. In order to determine the carbonyl content, a calibration curve was built measuring the absorbance at $482 \mathrm{~nm}$ of the reaction solutions with different amounts of a $0.0055 \mathrm{M}$ aqueous solution of glucose: $0.025,0.030,0.040$, $0.050,0.060,0.075,0.100 \mathrm{~mL}$, corresponding to $0.1375,0.1650,0.2200,0.2750,0.3300,0.4125$, $0.5500 \mu \mathrm{mol}$ of glucose in $10 \mathrm{~mL}$. Formazane solutions follow Beer's law in the calibration region (Strlič and Pihlar 1997). Therefore, a calibration graph plotting Abs at $482 \mathrm{~nm}$ versus $\mu \mathrm{mol}$ of glucose allows to evaluate the carbonyl content $(\mu \mathrm{mol})$. Figure 1 shows the calibration line $\left(\mathrm{R}^{2}=0.994\right)$ obtained, which is defined by the following equation:

$\operatorname{Abs}(482 \mathrm{~nm})=-0.43+2.91 \mu \mathrm{mol}_{\text {gluc }}$

It can be noted that the slope is very close to that found by Strlič and Pihlar (1997). According to Eq. 2, the concentration of glucose for which the absorbance measured is zero is equal to $0.15 \mu \mathrm{mol}$ in $10 \mathrm{~mL}$ of solution. This limit of detection was ascribed to the inherent loss of formazane (Strlič and Pihlar 1997).

At least two measurements of carbonyl content were carried out on each paper sample. The mean uncertainty of carbonyl content determinations was evaluated to be about $\pm 6 \%$, except for the RU paper $(23 \%)$.

\section{Results and discussion}

Figures 2 and 3 show the total carbonyl contents per gram of paper and the corresponding DP values as a function of oxidation time for the non-recycled and recycled papers, respectively.

As expected, the carbonyl content increases, and the DP decreases with increasing oxidation time. According to Margutti et al. (2001), the acidity of the periodate solution can also contribute to

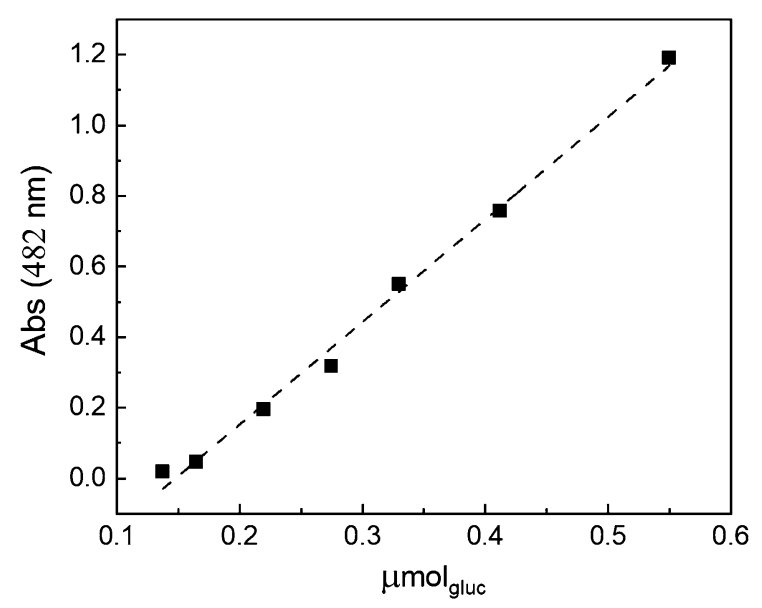

Fig. 1 Calibration line for the determination of carbonyl content 

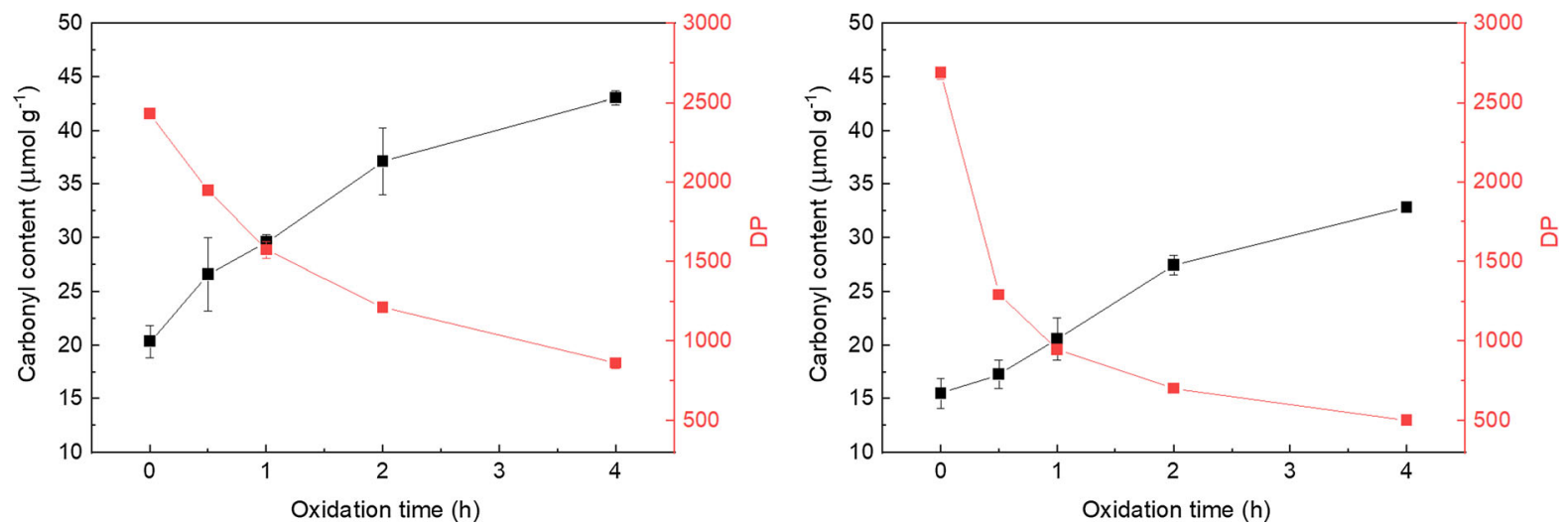

Fig. 2 Carbonyl contents $\left(\mu \mathrm{mol} \mathrm{g}{ }^{-1}\right.$ ) and DP values as a function of oxidation time for the A (left) and Wh (right) papers. Vertical lines indicate the standard deviations
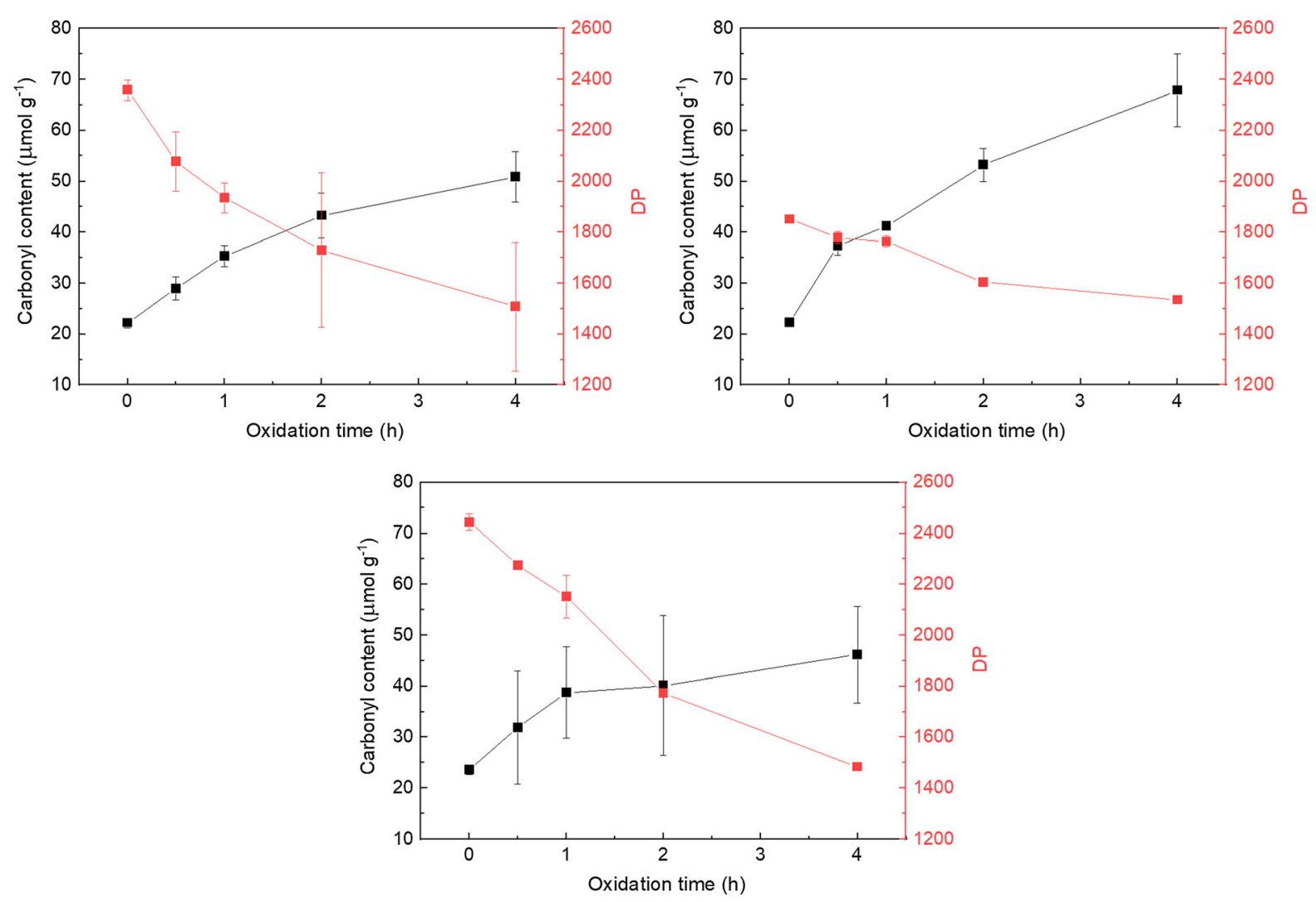

Fig. 3 Carbonyl contents $\left(\mu \mathrm{mol} \mathrm{g}{ }^{-1}\right.$ ) and corresponding DP values as a function of oxidation time for the RN (top left), RW (top right) and RU (bottom) papers. Vertical lines indicate the standard deviations

depolymerisation. The diagrams of Figs. 2 and 3 highlight at first glance that oxidation causes a sizeable decrease of DP values, especially for the two nonrecycled papers. A decrease of about $65 \%$ and $80 \%$ from the initial DP was measured after $4 \mathrm{~h}$ of oxidation for the A and Wh papers, respectively. The decrease of DP values of the three non-recycled paper is smaller, that is, about $40 \%$ for $\mathrm{RN}$ and $\mathrm{RU}$, and less than $20 \%$ for RW. The highest increase in carbonyl content was measured for the RW paper, the carbonyl 
content of the most oxidised sample being three times as large as that of the non-oxidised sample (see top right panel of Fig. 3). It can be noted that the values found for the carbonyl content of oxidised samples of the RU paper (see bottom panel of Fig. 3) are characterised by a large variance. In addition to an intrinsic error of the method for carbonyl content determinations, as reported by Strlič and Pihlar (1997), a tentative explanation for the higher error measured in RU could be ascribed to heterogeneity of this paper. The carbonyl contents of the other types of paper after $4 \mathrm{~h}$ of oxidation is about twice as large as that measured on the corresponding non-oxidised samples. The different behaviour in terms of DP decrease with increasing carbonyl content for the five types of paper considered is clearly shown in Fig. 4, where DP is plotted versus carbonyl content.

A negative linear correlation between DP and carbonyl content was found for all kinds of paper $\left(\mathrm{R}_{\mathrm{A}}^{2}=0.98, \quad \mathrm{R}^{2}{ }_{\mathrm{Wh}}=0.64, \quad \mathrm{R}_{\mathrm{RN}}^{2}=0.99, \quad \mathrm{R}_{\mathrm{RW}}^{2}\right.$ $\left.=0.95, R_{R U}^{2}=0.85\right)$. The significantly smaller correlation coefficient found for $\mathrm{Wh}$ stems from the sizeable decrease of DP measured after only $30 \mathrm{~min}$ of oxidation.

Oxidation has been held accountable for favouring hydrolysis (Krässig 1993). Provided the DP value is sufficiently large and assuming no loss of monomers, the kinetic of paper degradation for random acidhydrolytic reactions follows a first-order law with respect to the number of unbroken glycosidic bonds, which leads to the Ekenstam equation (Eq. 3) (Ekenstam 1936):

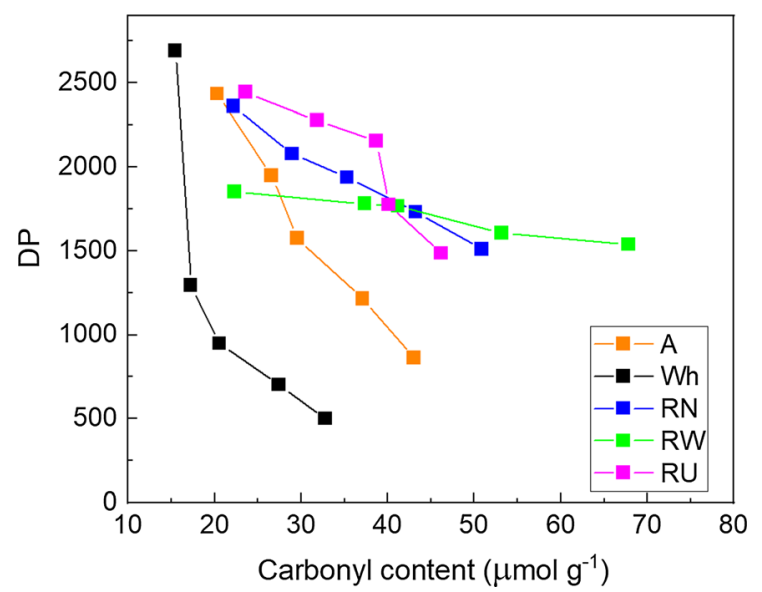

Fig. 4 DP as a function of carbonyl content $\left(\mu \mathrm{mol} \mathrm{g}{ }^{-1}\right)$ for the five types of paper considered
$\frac{1}{\mathrm{DP}}-\frac{1}{\mathrm{DP}_{0}}=\mathrm{kt}$

where DP and $\mathrm{DP}_{0}$ represent the degree of polymerisation of cellulose at time $t$ and 0 , respectively, and $k$ is the rate constant $\left(\mathrm{t}^{-1}\right)$. In analogy with the Ekenstam equation, Fig. 5 displays plots of the reciprocal DP versus oxidation time (instead of the degradation time) for non-recycled and recycled papers.

Figure 5 shows that, at least for our relatively short oxidation times, the plots display good linear correlations. In accordance with Eq. 3, the slopes lead to the evaluation of the corresponding pseudo rate constants. Table 1 reports these values and the corresponding correlation coefficients $\left(\mathrm{R}^{2}\right)$.

This approach also highlights that the three recycled papers are less sensitive to the oxidation treatment in terms of depolymerisation. This behaviour can be ascribed to different extents of crystallinity of the samples, as suggested by Łojewski et al. (2010). The trend of crystallinity index values calculated as the ratio between the FTIR absorbance at 1372 and $2900 \mathrm{~cm}^{-1}$ (Kato and Cameron 1999; Łojewski et al. 2010) is $\mathrm{Wh}<\mathrm{A}<\mathrm{RW}<\mathrm{RU}<\mathrm{RN}$. The higher crystallinity of the recycled papers can thus be associated with a higher resistance to depolymerisation. Interestingly, the most sensitive paper resulted to be Wh, which is made of pure cellulose, with no ash, lignin and additives, that is, the most expensive among the five papers considered. The high sensitivity of model paper likely stems from the absence of alkaline reserve. However, lignin content may also play a role

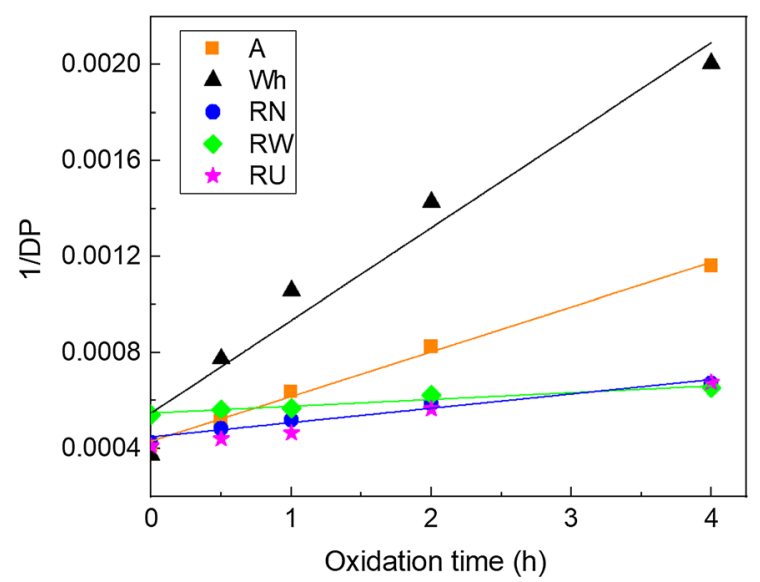

Fig. 5 Reciprocal DP as a function of oxidation time for the non-recycled and recycled papers considered 
Table 1 Pseudo rate constants calculated for the papers considered with the corresponding uncertainties and correlation coefficients $\left(\mathrm{R}^{2}\right)$

\begin{tabular}{lll}
\hline Paper sample & $\mathrm{k} \times 10^{5}\left(\mathrm{~h}^{-1}\right)$ & $\mathrm{R}^{2}$ \\
\hline A & $18.66 \pm 0.71$ & 0.996 \\
Wh & $38.62 \pm 4.70$ & 0.96 \\
RN & $5.985 \pm 0.65$ & 0.97 \\
RW & $2.840 \pm 0.44$ & 0.93 \\
RU & $6.814 \pm 0.43$ & 0.99 \\
\hline
\end{tabular}

in these differences. It has been reported that lignincontaining pulps are significantly affected in terms of yellowing (due to an increase of carbonyl groups, which are chromophores) upon oxidation, while maintaining their strength and DP (Schmidt et al. 1995). Future developments of the present study could investigate the role of lignin.

A previous study (Margutti et al. 2001) has reported on the effects of different concentrations of sodium periodate oxidation on Whatman filter paper No 1 $(\mathrm{Wh})$ in terms of [ $\eta]$ and DP. Viscometry was performed using the CED solvent, but the DP values were calculated using Eq. 1 with different coefficients. Therefore, for the sake of direct comparison with the present DP values, those reported by Margutti et al. (2001) were recalculated using the coefficients suggested by Evans and Wallis (1987) (see Eq. 1). The comparison in terms of reciprocal of DP as a function

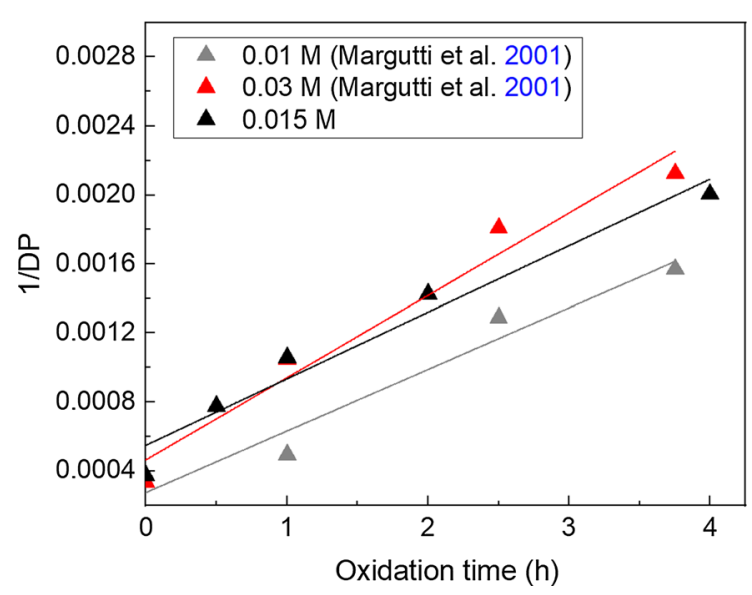

Fig. 6 Reciprocal of DP as a function of oxidation time for Wh paper: present results (black) and data reported in Margutti et al. (2001) (red and grey) of oxidation time for Whatman paper samples is displayed in Fig. 6.

A good linearity is also observed for the data previously reported (Margutti et al. 2001). It is worth noting that the plot obtained in the present study by oxidation in $0.015 \mathrm{M} \mathrm{KIO}_{4}$ is placed in the middle between those derived from Margutti et al. (2001). Table 2 compares the evaluated pseudo rate constants for Wh oxidised in 0.01 and $0.03 \mathrm{M} \mathrm{NaIO}_{4}$ with that obtained here.

It has recently been reported (Coppola et al. 2018a) that the degradation rates found for RW and A, aged at different conditions of temperature and water vapour pressure, are comparable within the experimental uncertainties, although those found for the recycled paper (RW) are slightly higher than those found for the non-recycled paper (A). The present results show that the extent of depolymerisation due to oxidation with periodate, in contrast to that due to accelerated ageing, is influenced by the type of paper.

It is well known that $\mathrm{pH}$ plays a crucial role in the kinetics of paper degradation. An increase of $\mathrm{pH}$ from 4 to 8 was found to cause a decrease of the degradation rate of pure cellulose by a factor of 3 (Kočar et al. 2005). Table 3 reports the $\mathrm{pH}$ values measured for the five types of paper considered here, following the procedure reported by Strlič et al. (2004).

It is to be noted that the $\mathrm{pH}$ values of the $\mathrm{A}$ and $\mathrm{RW}$ papers are in good agreement with those found in a previous study (Coppola et al. 2018a). However, it is worth noting that a decrease of the $\mathrm{pH}$ values by at least one unit upon addition of an electrolyte (few drops of $\mathrm{NaCl}$ solution) was observed. This finding is plausibly to be ascribed to an instrumental error when the ionic strength is extremely low (Strlič et al. 2004). Accordingly, the $\mathrm{pH}$ of Whatman paper should be nearly neutral (Kočar et al. 2005; Neves et al. 2009), as it is made of pure cellulose, free from additives.

Table 2 Pseudo rate constants (see text) for Wh paper obtained in the present study and those derived from Margutti et al. (2001)

\begin{tabular}{|c|c|c|c|}
\hline Oxidant & Concentration $\left[\mathrm{mol} \mathrm{L}^{-1}\right]$ & $\mathrm{k} \times 10^{5}\left(\mathrm{~h}^{-1}\right)$ & $\mathrm{R}^{2}$ \\
\hline $\mathrm{NaIO}_{4}$ & 0.01 & $35.75 \pm 4.94$ & 0.96 \\
\hline $\mathrm{NaIO}_{4}$ & 0.03 & $47.76 \pm 6.44$ & 0.96 \\
\hline $\mathrm{KIO}_{4}$ & 0.015 & $38.62 \pm 4.70$ & 0.96 \\
\hline
\end{tabular}


Table $3 \mathrm{pH}$ values (average of three measurements) and standard deviations of the non-oxidised papers

\begin{tabular}{ll}
\hline Paper sample & $\mathrm{pH}$ \\
\hline $\mathrm{A}$ & $8.4 \pm 0.2$ \\
$\mathrm{Wh}$ & $8.5 \pm 0.3$ \\
$\mathrm{RN}$ & $9.3 \pm 0.2$ \\
$\mathrm{RW}$ & $8.6 \pm 0.1$ \\
$\mathrm{RU}$ & $9.1 \pm 0.1$ \\
\hline
\end{tabular}

Probably, further work on the correct procedure and equipment to determine $\mathrm{pH}$ values in solutions with very low ionic strength should be carried out. Regardless of these limits, the $\mathrm{pH}$ values measured for all kinds of paper did not change significantly with the oxidation time. The $\mathrm{pH}$ values of the three recycled papers analysed resulted to be somewhat higher than those of the non-recycled ones (see Table 3). This finding can account for the lower rate of degradation in terms of DP. However, this is not the only factor as the $\mathrm{A}$ and $\mathrm{RW}$ papers have comparable $\mathrm{pH}$ values but sizeably different pseudo rate constants (see Table 1).

\section{Conclusions}

The effects of periodate oxidation on five different types of paper, recycled and non-recycled, were evaluated. Previous accelerated ageing experiments have shown that two types of paper analysed in the present study (the non-recycled and recycled papers labelled A and RW, respectively) degrade similarly. However, the present results indicate that oxidation influences the chemical properties (degree of polymerisation (DP) and carbonyl content) of the investigated paper types to different extents, thus stimulating further work to study these different behaviours. The formation of carbonyl groups in the recycled papers is found to be larger than that in the non-recycled ones. Nevertheless, the present results show that the oxidation process causes a larger degradation in the non-recycled papers in terms of reduction of the average DP, as measured with viscometry. Regardless of these differences, the present findings suggest that oxidation by the specific agent periodate, which attacks the $\mathrm{C} 2-\mathrm{C} 3$ ring bond, favours random hydrolysis with scission of the glycosidic bonds. The degradation data obtained in the present study for the model Whatman paper (Wh) oxidised with a periodate solution are comparable to those previously reported in the literature.

For the first time, this study shows that, in accordance with the Ekenstam equation, the reciprocal of DP as a function of oxidation time is found to give good linear correlations for all types of paper investigated. The degradation rates calculated for the nonrecycled papers result to be higher than those of the recycled papers. The most sensitive paper in terms of DP decrease results to be the model Wh paper made of pure cellulose, in line with the absence of alkaline reserves. More in general, the three less expensive (recycled) papers analysed here prove to be degraded to a lesser extent by the action of a specific oxidant.

Acknowledgments $\mathrm{AM}$ and FC thank the Italian Ministero dell'Istruzione, dell'Università e della Ricerca for financial support.

Funding Open access funding provided by Alma Mater Studiorum - Università di Bologna within the CRUI-CARE Agreement.

Availability of data and material Data generated during this study are included in this article.

\section{Compliance with ethical standards}

Conflict of interest The authors declare that they have no competing interests.

Open Access This article is licensed under a Creative Commons Attribution 4.0 International License, which permits use, sharing, adaptation, distribution and reproduction in any medium or format, as long as you give appropriate credit to the original author(s) and the source, provide a link to the Creative Commons licence, and indicate if changes were made. The images or other third party material in this article are included in the article's Creative Commons licence, unless indicated otherwise in a credit line to the material. If material is not included in the article's Creative Commons licence and your intended use is not permitted by statutory regulation or exceeds the permitted use, you will need to obtain permission directly from the copyright holder. To view a copy of this licence, visit http://creativecommons.org/licenses/by/4.0/.

\section{References}

Ali M, Emsley AM, Herman H, Heywood RJ (2001) Spectroscopic studies of the ageing of cellulosic paper. Polymer 42:2893-2900. 3861(00)00691-1 https://doi.org/10.1016/S0032-

Area MC, Cheradame H (2011) Paper aging and degradation: recent findings and research methods. BioResources 6:5307-5337 
ASTM D778-97 (2007) Test methods for hydrogen ion concentration $(\mathrm{pH})$ of paper extracts (hot-extraction and coldextraction procedures)

Barański A, Dziembaj R, Konieczna A, Kowalski A, Łagan JM, Proniewicz L (2000) Methodology of kinetic investigation of cellulose degradation. In: III Congress of chemical technology, 5-8 October 2000, Gliwice. Technologia Chemiczna na Przełomie Wieków, Wydawnictwo Stałego Komitetu Kongresów Technologii Chemicznej (Chemical Technology Between Centuries, A Publication of the Permanent Committee of Chemical Technology Congress), Gliwice, pp 441-450. http://www2.chemia.uj.edu.pl/kp/ deg_kinetics.pdf. Accessed 3 Aug 2020

Barański A, Konieczna-Molenda A, Łagan JM, Proniewicz LM (2003) Catastrophic room temperature degradation of cotton cellulose. Restaurator 24:36-45. https://doi.org/10. 1515/REST.2003.36

Bicchieri M, Bella M, Semetilli F (1999) A quantitative measure of borane tert-butylamine complex effectiveness in carbonyl reduction of aged papers. Restaurator 20:22-29. https://doi.org/10.1515/rest.1999.20.1.22

Bicchieri M, Monti M, Piantanida G, Sodo A (2016) Effects of gamma irradiation on deteriorated paper. Radiat Phys Chem 125:21-26. https://doi.org/10.1016/j.radphyschem. 2016.03.005

Biermann CJ (1996) Handbook of pulping and papermaking. Academic Press, San Diego

CEPI (2009) FSC rules on post- and pre-consumer reclaimed material. Position paper

CEPI (2017) Key statistics. https://www.cepi.org/key-statisticsreport-2017/. Accessed 4 Aug 2020

Coppola F, Modelli A, Cigić IK, Mahgoub H, Strlič M (2017) Investigation of the degradation of contemporary papers aged at different conditions of temperature and relative humidity. Poster. In: 3rd International SEAHA conference, 19-20 June 2017, Brighton

Coppola F, Modelli A, Strlič M, Andretta M, Scagnolari F (2018a) Kinetics of degradation of non-recycled and recycled contemporary paper. Cellulose 25:5337-5347. https://doi.org/10.1007/s10570-018-1951-8

Coppola F, Fiorillo F, Modelli A, Montanari M, Vandini M (2018b) Effects of $\gamma$-ray treatment on paper. Polym Degrad Stab 150:25-30. https://doi.org/10.1016/j. polymdegradstab.2018.02.004

Dupont A-L, Mortha G (2004) Comparative evaluation of sizeexclusion chromatography and viscometry for the characterisation of cellulose. J Chromatogr A 1026:129-141. https://doi.org/10.1016/j.chroma.2003.11.002

Ekenstam AA (1936) Über das verhalten der cellulose in mineralsäure-lösungen, II. Mitteil.: kinetisches studium des abbaus der cellulose in säure-lösungen. Berichte Dtsch Chem Ges B Ser 69:553-559. https://doi.org/10.1002/cber. 19360690315

EPRC (2019) Monitoring report 2018. Full text in PDF format: https://www.paperforrecycling.eu/download/1007/. Accessed 4 Aug 2020

Evans R, Wallis A (1987) Comparison of cellulose molecular weights determined by high performance size exclusion chromatography and viscometry. In: 4th international symposium on wood and pulping chemistry. 27-30 April 1987, Paris
Flory PJ (1953) Determination of molecular weights. In: Flory PJ (ed) Principles of polymer chemistry. Cornell University Press, Ithaca, pp 266-316

Hunter D (1978) Papermaking: the history and technique of an ancient craft. Dover Publications, New York

ISO 5351 (2010) Pulps - determination of limiting viscosity number in cupri-ethylenediamine (CED) solution

Jeong M-J, Dupont A-L, de la Rie ER (2014) Degradation of cellulose at the wet-dry interface. II. Study of oxidation reactions and effect of antioxidants. Carbohydr Polym 101:671-683. https://doi.org/10.1016/j.carbpol.2013.09. 080

Kačík F, Kačíková D, Jablonský M, Katuščák S (2009) Cellulose degradation in newsprint paper ageing. Polym Degrad Stab 94:1509-1514. https://doi.org/10.1016/j. polymdegradstab.2009.04.033

Kato KL, Cameron RE (1999) Structure-property relationships in thermally aged cellulose fibers and paper. J Appl Polym Sci 74:1465-1477. https://doi.org/10.1002/(SICI)10974628(19991107)74:6<1465::AID-APP20>3.0.CO;2-3

Kočar D, Strlič M, Kolar J, Rychlý J, Matisová-Rychlá L, Pihlar B (2005) Chemiluminescence from paper III: the effect of superoxide anion and water. Polym Degrad Stab 88:407-414. https://doi.org/10.1016/j.polymdegradstab. 2004.12.005

Kolar J (1997) Mechanism of autoxidative degradation of cellulose. Restaurator 18:163-176. https://doi.org/10.1515/ rest.1997.18.4.163

Krässig HA (1993) Cellulose: structure, accessibility and reactivity. Gordon and Breach Science Publishers, Philadelphia

Łojewska J, Miśkowiec P, Łojewski T, Proniewicz LM (2005) Cellulose oxidative and hydrolytic degradation: in situ FTIR approach. Polym Degrad Stab 88:512-520. https:// doi.org/10.1016/j.polymdegradstab.2004.12.012

Łojewski T, Zięba K, Knapik A, Bagniuk J, Lubańska A, Łojewska J (2010) Evaluating paper degradation progress. Cross-linking between chromatographic, spectroscopic and chemical results. Appl Phys Mater Sci Process 100:809-821. https://doi.org/10.1007/s00339-010-5657-5

Łojewski T, Zięba K, Kołodziej A, Łojewska J (2011) Following cellulose depolymerization in paper: comparison of size exclusion chromatography techniques. Cellulose 18:1349. https://doi.org/10.1007/s10570-011-9562-7

Malesic J, Kolar J, Strlič M (2002) Effect of pH and carbonyls on the degradation of alkaline paper-factors affecting ageing of alkaline paper. Restaur Int J Preserv Libr Arch Mater 23:145-153. https://doi.org/10.1515/REST.2002. 145

Margutti S, Conio G, Calvini P, Pedemonte E (2001) Hydrolytic and oxidative degradation of paper. Restaurator 22:67-83. https://doi.org/10.1515/REST.2001.67

Mosca Conte A, Pulci O, Knapik A, Bagniuk J, Del Sole R, Łojewska J, Missori M (2012) Role of cellulose oxidation in the yellowing of ancient paper. Phys Rev Lett. https:// doi.org/10.1103/PhysRevLett.108.158301

Nevell TP (1985a) Degradation of cellulose by acids, alkalis, and mechanical means. In: Nevell TP, Zeronian SH (eds) Cellulose chemistry and its applications. Ellis Horwood, Chichester, pp 223-242 
Nevell TP (1985b) Oxidation of cellulose. In: Nevell TP, Zeronian SH (eds) Cellulose chemistry and its applications. Ellis Horwood, Chichester, pp 243-265

Nevell TP, Zeronian SH (1985) Chemical structure of cellulose. In: Nevell TP, Zeronian SH (eds) Cellulose chemistry and its applications. Ellis Horwood, Chichester, pp 15-29

Neves ER, Schäfer S, Phillips A, Canejo J, Macedo MF (2009) Antifungal effect of different methyl and propyl paraben mixtures on the treatment of paper biodeterioration. Int Biodeterior Biodegrad 63:267-272. https://doi.org/10. 1016/j.ibiod.2008.07.011

Porck HJ (2000) Rate of paper degradation: the predictive value of artificial aging tests. European Commission on Preservation and Access, Amsterdam

Roberts JC (1996) The chemistry of paper. Royal Society of Chemistry, Cambridge

Röhrling J, Potthast A, Rosenau T, Borgards A, Sixta H, Kosma P (2002) A novel method for the determination of carbonyl groups in cellulosics by fluorescence labelling. 1. Method development. Biomacromol 3:959-968. https://doi.org/10. 1021/bm020029q

Schmidt JA, Rye CS, Gurnagul N (1995) Lignin inhibits autoxidative degradation of cellulose. Polym Degrad Stab 49:291-297. https://doi.org/10.1016/01413910(95)87011-3

Sistach MC, Ferrer N, Romero MT (1998) Fourier transform infrared spectroscopy applied to the analysis of ancient manuscripts. Restaurator 19:173-186. https://doi.org/10. 1515/rest.1998.19.4.173

Strang T, Grattan D (2009) Temperature and humidity considerations for the preservation of organic collections-the isoperm revisited. E-Preserv Sci 6:122-128

Strlič M, Kolar J (2003) Size exclusion chromatography of cellulose in $\mathrm{LiCl} / \mathrm{N}, \mathrm{N}$-dimethylacetamide. J Biochem Biophys Methods 56:265-279. https://doi.org/10.1016/ S0165-022X(03)00064-2

Strlič M, Pihlar B (1997) Determination of reducing carbonyl groups in cellulose in the solvent system $\mathrm{LiCl} / \mathrm{N}, \mathrm{N}-$ dimethylacetamide. Fresenius J Anal Chem 357:670-675. https://doi.org/10.1007/s002160050232

Strlič M, Kolar J, Žigon M, Pihlar B (1998) Evaluation of sizeexclusion chromatography and viscometry for the determination of molecular masses of oxidised cellulose. J Chromatogr A 805:93-99. https://doi.org/10.1016/ S0021-9673(98)00008-9

Strlič M, Kolar J, Kočar D, Drnovšek T, Šelih VS, Susič R, Pihlar B (2004) What is the pH of alkaline paper? E-Preserv $1: 35-47$
Strlič M, Kolar J, Scholten S (2005a) Paper and durability. In: Strlič M, Kolar J (eds) Ageing and stabilisation of paper. National and University Library, Ljubljana, pp 3-8

Strlič M, Kolar J, Pihlar B (2005b) Methodology and analytical techniques in paper stability studies. In: Strlič M, Kolar J (eds) Ageing and stabilisation of paper. National and University Library, Ljubljana, pp 25-44

Strlič M, Kralj Cigić I, Možir A, De Bruin G, Kolar J, Cassar M (2011) The effect of volatile organic compounds and hypoxia on paper degradation. Polym Degrad Stab 96:608-615. https://doi.org/10.1016/j.polymdegradstab. 2010.12.017

Szabolcs O (1961) Eine kolorimetrische Methode zur Bestimmung der reduzierenden Carbonylgruppen in der cellulose. Paper 15:41-44

TAPPI T430 cm-09 (2009) Copper number of pulp, paper, and paperboard

TAPPI T509 om-15 (2015) Hydrogen Ion concentration (pH) of paper extracts (cold extraction method)

TAPPI T529 om-14 (2014) Surface pH measurement of paper

Tétreault J, Bégin P, Paris-Lacombe S, Dupont A-L (2019) Modelling considerations for the degradation of cellulosic paper. Cellulose 26:2013-2033. https://doi.org/10.1007/ s10570-018-2156-x

Varma AJ, Chavan VB (1995) A study of crystallinity changes in oxidised celluloses. Polym Degrad Stab 49:245-250. https://doi.org/10.1016/0141-3910(95)87006-7

Whitmore PM, Bogaard J (2009) The effect of oxidation on the subsequent oven aging of filter paper. Restaurator 16:10-30. https://doi.org/10.1515/rest.1995.16.1.10

Zervos S (2010) Natural and accelerated ageing of cellulose and paper: a literature review. In: Lejeune A, Deprez T (eds) Cellulose: structure and properties, derivatives and industrial uses. Nova Science Publishers, New York, pp 155-203

Zou X, Uesaka T, Gurnagul N (1996) Prediction of paper permanence by accelerated aging I. Kinetic analysis of the aging process. Cellulose 3:243-267. https://doi.org/10. 1007/BF02228805

Publisher's Note Springer Nature remains neutral with regard to jurisdictional claims in published maps and institutional affiliations. 